Status : Original Study

Received: December 2013

Accepted: April 2014

E-Journal of New World Sciences Academy

\author{
Haydar Tuna \\ Gazi University, haydartuna@hotmail.com, Ankara-Turkey \\ O. Ayhan Erdem \\ GaziUniversity, ayerdem@gazi.edu.tr, Ankara-Turkey
}

http://dx.doi.org/10.12739/NWSA.2014.9.2.2A0085

\title{
ORMAN YANGIN DAVRANIŞININ ÇOK DEĞİŞKENLİ REGRESYONLA TAHMİN EDİLMESİ ÖZET
}

Bu çalışmada, 21 kontrollü örtü yangını çıkartılmış, elde edilen 151 veri seti, dört farklı regresyon modeliyle denenerek, orman yangın davranışlarının modellenmesi gerçekleştirilmiştir. Geliştirilen bu modellerin tamamında bağımlı değişken olarak yanan alan, bağımsız değişken olarak ise diri örtü, ölü örtü, humus, sıcaklık, çiğ noktası, bağıl nem, rüzgâr hızı ve zaman değerleri kullanılmıştır. Bu regresyon modellerinden bağımsız değişkenlerin katsayılarının birbiriyle çarpımını ve karelerini içeren eğri, $R^{2} 0.854 \quad(p<0.01$ ve RMS=10.2) değeriyle diğerlerine göre daha başarılı çıkmıştır. Ayrıca elde edilen regresyon eğrilerinin tamamında $p$ değeri 0.01 'in altında kalmıştır. Bağımsız değişkenlerin katsayılarında ise p değeri en düşük olan rüzgâr en etkili meteorolojik değişken bulunmuştur. Rüzgâr dışında en etkili diğer meteorolojik değişkenler ise sırasıyla sıcaklık, nem ve çiğ noktası olmuştur

Anahtar Kelimeler: Regresyon Analizi, Çok Değişkenli Regresyon Analizi, Yangın Davranış Modelleme, Yangın Davranış Tahmini, Yangın Yayılım Modeli

\section{FOREST FIRE BEHAVIOR PREDICTION WITH MULTIVARIATE REGRESSION ABSTRACT}

In this study, 151 data set was obtained from 21 controlled grassland fires and then four different regression models were tested with this data and forest fire behavior was tried to model. In all of these models, it was used the burned area as the dependent variable and weed, litter, humus, temperature, dew point, relative humidity, wind speed and time as independent variable. One of these regression models that contains coefficients of independent variables multiplied together and its square was $\mathrm{R}^{2}$ with the value of $0.854 \quad(\mathrm{p}<0.01$ and $\mathrm{RMS}=10.2)$ was more successful than other regression models. Also, obtained regression curves in all the p-value was below 0.01. ind have been found the most effective meteorological variable whose $p$ value in the coefficients of independent variables is the lowest. Temperature, humidity and dewpoint have been the most effective meteological variables following the wind.

Keywords: Regression Analysis, Multivariate Regression Analysis, Fire Behavior Modeling, Fire Behavior Prediction, Fire Propagation Model 
Tuna, H. ve Erdem, O.A.

NWSA-Technological Applied Sciences, 2A0085, 9, (2), 13-21.

\section{GIRIŞ (INTRODUCTION)}

Bir yangınının başlayabilmesi için yanma üçgeninde geçen ısı kaynağı, oksijen ve yakıta gereksinim vardır. Fakat diğerlerinden farkıı olarak açık havada oksijen doğal olarak bulunduğundan orman yangınlarının başlaması için sadece ısı kaynağına ve yakıta ihtiyaç vardır. Yakıt, orman yüzeyinde bulunan ağaç dallarını, kozalakları, ince yanıcıları vb. yanma özelliği olan maddeleri kapsar. Isı kaynağı ise bu yanıcı maddelerin tutuşma sıcaklığına daha çabuk ulaşmasını sağlar. Tüm şartlar sağlandığında ise orman örtüsünde yangın başlamış olur.

Ormancılık açısından yangınlara en kısa sürede müdahale edilip, söndürülmesi esastır. Çünkü yangına ne kadar geç müdahale edilirse yangının enerjisi ve yıkım miktarı o kadar fazla olacaktır. Tüm bu söndürme faaliyetleri içindeki en önemli husus ise çıkan bir yangının meteorolojik şartlara, topografyaya, bitki örtüsüne göre ve zamana bağlı olarak nereye ulaşacağının bilinmesidir. Bu tahmin edildiği takdirde alınan önlemlerle yangın daha çabuk söndürülecektir. Örneğin yangının ilerleyeceği nokta tahmin edilip, bu bölgeye yangının sıçramasını engelleyici şerit açılması alınacak önlemlerden bir tanesidir. Fakat yangında çok yüksek ısı miktarları açığa çıktığı için zamanlama çok önemlidir. Örneğin şerit açma işleminden önce yangın bölgeye ulaşırsa, işçiler zarar görebilir ve can kaybı meydana gelebilir ya da bu işlem için gecikilirse, yangın daha büyük bir sahaya sıçrayabilir. İşte bu zamanlamayı doğru yapabilmek için deneysel, istatistiksel tabanlı birçok sistem geliştirilmiştir. Bu sistemlerin tamamının amacı ise yangın davranışının tahmin edilmesidir.

Bu çalışmada, kullanılan çok değişkenli regresyon tekniği istatistiksel tabanlıdır. Bu teknikleri kullanılarak yangından önce ve sonra, yangın devam ederken çeşitli tahminler yapılabilir. Örneğin yangın çıkmadan önce tehlike derecesinin ve insan faktörünün etkisi bulunabilir. Buna ek olarak yangın devam ederken davranış modellenebilir ya da yangın söndükten sonra oluşan yıkım tespit edilip, gerekli ağaçlandırma çalışması planlanabilir.

İklimsel olarak belli dönemlerde yangın çıkması ve ilerlemesi daha kolay olur. Bu dönemlerde yangının çıkma riski tehlike derecesi olarak adlandırılan, sayısal bir değere dönüştürülüp, sınıflandırıldığı takdirde ormanların korunması ile ilgili tedbirler alınabilir. Bu tehlike derecesi, geçmişte çıkan yangınlara ait meteorolojik ve coğrafi değişkenlere, orman örtüsüne bakılarak hassas bölgelerin bulunması esasına göre çeşitli istatistiksel hesaplamalar yapılarak bulunur [1, 2, 3 ve 4].

Orman yangınlarının çıkmasını etkileyen bir diğer husus olan insan faktörü de istatistiksel hesaplamalara konu olmuştur. Örneğin; orman olan bölgeye yerleşim yerlerinin uzaklığı, nüfus sayısı, suç oranları gibi faktörler insan faktörünün yangın üzerinde etkisini belirlemektedir. Bu etki, regresyon veya diğer yöntemlerle bulunup coğrafi bilgi sistemlerine yansıtılarak yangına daha hassas bölgeler tespit edilebilmektedir [5 ve 6].

Bu çalışmanın konusu olan yangın yayılımı da regresyon analizinin konuları arasındadır. Buradaki temel fikir, yangını etkileyen koşulların (meteorolojik, coğrafi, zaman vb.) bağımlı değişken ve yangın neticesinde ortaya çıkan alan, hız, açığa çıkan enerji gibi büyüklüklerin de bağımsız değişken olarak kabul edilip, buna göre davranış modellerinin tasarlanmasıdır [7 ve 8]. 
Tuna, H. ve Erdem, O.A. NWSA-Technological Applied Sciences, 2A0085, 9, (2), 13-21.

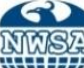

Yangın bittikten sonra yanan alanların tahmin edilmesi ve silvi kültür olarak adlandırılan çalışmaların yapılması için yine istatistik kurallarından faydalanılarak, bitki örtüsündeki değişiklikler hesaplanabilir. Bunun için son yıllarda orman örtüsünün uydudan farklı zaman aralıklarında çekilmiş görüntüleri arasındaki farklılıklardan faydalanılmaya başlanmıştır [9, 10 ve 11].

\section{2. ÇALIŞMANIN ÖNEMI (RESEARCH SIGNIFICANCE)}

Çıkan bir yangın ile ilgili yapılacak en önemli işlem, en kısa sürede söndürülmesidir. Çünkü yanma olayı fotosentezin tersidir ve açığa yüksek miktarda ısı çıkarır. Bu sıcaklık değerlerinde insan eliyle müdahale etmek ise can ve mal kayıplarına yol açar.

Bir orman yangını, öncelikli olarak örtüde başlar. Daha sonra yayılarak ortam da uygunsa tepeye çıkar ve bu andan sonra yangının söndürülmesi zor hale gelir. Bu yüzden yangının daha tepeye sıçramadan söndürülmesi, daha büyük olabilecek zararları azaltır.

Bu çalışmada ise regresyon teknikleri kullanılarak, çıkan bir örtü yangının belli süre sonunda ne kadar alan yakacağı bulunmuştur. Bunu gerçekleştirebilmek için çeşitli deneme yangınları çıkartılmış ve eliptik yörünge izleyen yangına ilişkin meteorolojik, bitki örtüsü ve zaman bilgisinden faydalanarak, yanan alan dört farklı regresyon modeliyle tahmin edilmiştir.

Çalışma bu haliyle devam eden bir örtü yangının davranışını tahmin etmektedir. Böylelikle yangının büyümeden çok kısa sürede söndürülmesi ve gerekli tedbirlerinin alınması sağlanabilir. Bunun dışında benzer parametrelerle tepe yangınlarının da davranışı modellenebilir.

\section{DENEYSEL YÖNTEM (EXPERIMENTAL METHOD)}

Bu çalışmayı gerçekleştirebilmek için öncelikli olarak Orman Genel Müdürlüğünden kontrollü deneme yangınları çıkartabilmek için izin alınmıştır. Bu izin kapsamında saha olarak Antalya Orman Bölge Müdürlüğüne bağlı, kuzey batıda yer alan Resim 1'deki konuma sahip, Düzlerçamı İşletmesinde diri örtü kapalılığı 0-10, 10-30 ve 30-70 olan iki bölge seçilmiştir. Bunun dışında bölgeler homojene yakın bir dağılım seyrettiği için ölü örtü ve humus örneği 5 farklı yerden alınmıştır. Aynı örnek alma işlemi diri örtü içinde yapılmıştır.

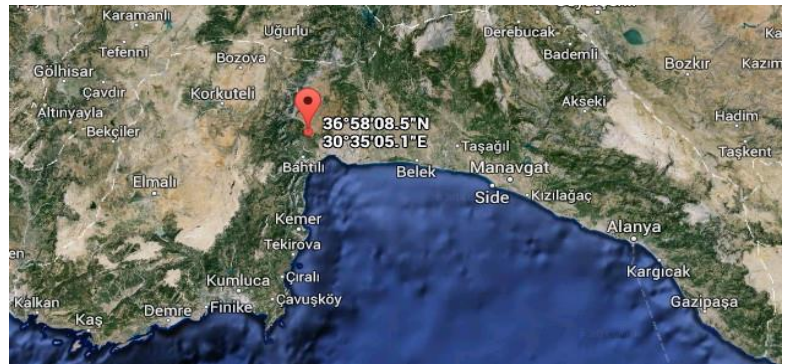

Resim 1. Düzlerçamı bölgesi harita koordinatları

(Picture 1. Map coordinates of Düzlerçamı district)

Alınan diri örtü çaplarına $(0.0-0.3 \mathrm{~mm}, 0.3-0.6 \mathrm{~mm}, 0.6 .-1.0 \mathrm{~mm}$, 1.0-2.5 mm) ve yaprak miktarına göre sınıflandırılmış daha sonra bu materyaller bir gün süreyle fırınlanmıştır. İşlemin sonunda bir çap sınıfına ait diri örtünün olması gereken miktarı, fırınlanmadan sonraki ağırlıklar orantılanarak Tablo 1'deki gibi bulunmuştur. 
Tuna, H. ve Erdem, O.A. NWSA-Technological Applied Sciences, 2A0085, 9, (2), 13-21.

Tablo 1. Diri örtü örneklerinin fırınlanmadan sonraki ağırlıkları

(Table 1 . Weed weights of samples after baking)

\begin{tabular}{|l|c|c|}
\hline Bölge & Diri Örtü Yoğunluğu (\%) & $\begin{array}{c}\text { Fırınlanmış Diri Örtü } \\
\text { Toplam Ağırığı (gr) }\end{array}$ \\
\hline 1.Bölge & $0-10$ & 135,63 \\
\hline 2.Bölge & $10-30$ & 153,72 \\
\hline 2.Bölge & $30-70$ & 518,98 \\
\hline
\end{tabular}

Benzer çalışma ölü örtü içinde gerçekleştirilmiştir. Bunun için ölü örtü çaplarına ayrılmış ve her bir sahadaki olması gereken ölü örtü miktarları fırınlanmış örneğe göre orantılanarak Tablo 2'deki gibi bulunmuştur.

Tablo 2. Ölü ört örneklerinin fırınlanmadan sonraki ağırlıkları (Table 2. Litter weights of samples after baking)

\begin{tabular}{|c|c|c|c|}
\hline Bölge & $\begin{array}{c}\text { Diri Örtü } \\
\text { Yoğunluğu ( }\end{array}$ & $\begin{array}{c}\text { Fırınlanmış Ölü } \\
\text { Örtü Ağlrlığı(gr) }\end{array}$ & $\begin{array}{c}\text { Fırınlanmış Humus } \\
\text { Ağırlığı (gr) }\end{array}$ \\
\hline 1.Bölge & $0-10$ & 91,42 & 123,56 \\
\hline 2.Bölge & $10-30$ & 229,22 & 538,18 \\
\hline 2.Bölge & $10-30$ & 272,23 & 1502,85 \\
\hline 2.Bölge & $30-70$ & 272,23 & 1502,85 \\
\hline
\end{tabular}

Arazi ölçümlerinden sonra yangın çıkartmak için gerekli düzenek Batı Akdeniz Orman Araştırma Enstitüsü ve Antalya Bölge Müdürlüğü koordinesinde kurulmuştur. Bunun için yangın çıkartılacak sahaya normal kamera düzeni kurulmuştur. Kameranın açısı odak uzunluğu da dikkate alınarak yangının tamamını görebilecek şekilde ayarlanmıştır. Ayrıca sisteme mobil olarak bütünleşmiş termal kamera sistemi de eklenmiştir. Bunun dışında kontrollü deneme yangınında olası tehlikeli durumların önüne geçmek için iki arasöz ve yangın ilk müdahale ekibi oluşturulmuştur.

Tüm bu yapılanlara ek olarak sistemde meteorolojik değişkenlerin ölçümünü yapmak için bir araç üzerine mobil istasyon kurulmuş ve istasyonun kalibrasyonu yapılmıştır. İstasyon üzerinde rüzgârın 2 metre yükseklikten ölçülmesi için gerekli düzenek, kontrollü deneme yangını çıkartılacak bölgeye yakın bir araç üzerine sabitlenmiştir.

Tüm güvenlik önlemleri alındıktan sonra bir noktadan kibrit kullanılarak örtü yangını başlatılmıştır. Belli zaman aralıklarında yangının yatay ve dikey olarak ilerleme miktarları ölçülmüştür. Sonuçta çıkartılan 21 kontrollü yangından, meteorolojik verileri, örtü bilgisini ve zamanı içeren 151 veri seti elde edilmiştir. Bu veri setinden, belli zaman aralığında yanan alan, elips formülü kullanılarak elde edilmiştir.

\section{REGRESYON ANALIZI (REGRESSION ANALYSIS)}

Regresyon analizi, iki ya da çok değişken arasındaki ilişkiyi bulmaya yarayan bir tekniktir. Bu yüzden regresyon iki değişkenli ve çok değişkenli olarak iki guruba ayrılır [12] .

İki değişkenli regresyon analizinde ilişki türü lineer, polinom ya da üstel olarak ifade edilen fonksiyonlar kullanllarak bulunur. Regresyondaki amaç ise bu ilişkiyi sağlayan en iyi denklemin bulunmasıdır. Örneğin iki değişkenli lineer regresyon $y=\beta_{0}+\beta_{1} x+\varepsilon$ şeklinde bir yapıya sahiptir. Burada y bağımlı değişken, x bağımsız değişken, $\beta_{0}$ eğrinin y eksenindeki kesişim noktası, $\beta_{1}$ doğrunun eğimini ve $\varepsilon$ hata değerini göstermektedir. Doğru denklemi bulunurken, örnekleme 
Tuna, H. ve Erdem, O.A. NWSA-Technological Applied Sciences, 2A0085, 9, (2), 13-21.

alınıp verileri kesen bir doğru elde edilir. Elde edilen bu doğrunun yöntemdeki temel prensip, oluşan hata miktarlarının kareleri toplamını en az yapan doğrunun bulunmasıdır.

İki değişkenli regresyon analizinde benzer yaklaşımlar polinom ve üstel fonksiyon kullanllan analizlerde de geçerlidir. Bu regresyon tekniklerinde de aynı şekilde hata kareleri toplamı en az olan denklem ve katsayıları bulunur.

Regresyon analizindeki diğer bir husus ise elde edilen bağımlı değişken değeri ile olması gereken değer arasındaki ilişkiyi belirlemeye yarayan korelasyon katsayısının bulunmasıdır. Elde edilen bu değer sıfıra doğru yaklaşırsa büyüklükler arasında zayıf bir ilişki, bire doğru yaklaşırsa kuvvetıi bir ilişki vardır. Eğer korelasyon değeri -1'e yaklaşırsa da bu sefer iki büyüklük arasında ters yönde bir kuvvetli bir ilişki mevcuttur.

Çok değişkenli regresyon ise birden fazla bağımsız değişkenin, bağımlı değişkeni etkilediği durumlarda ortaya çıkar. Örneğin tipik bir çok değişkenli regresyon eğrisi şu şekilde bir yapıya sahiptir:

$$
y=\beta_{0}+\beta_{1} X_{1}+\beta_{2} X_{2}+\beta_{3} X_{3}+\ldots \ldots \ldots \beta_{n} X_{n}+\varepsilon
$$

Burada y bağımıı değişkeni, $x_{1} . x_{n}$ bağımsız değişkenleri, $\beta_{0} . . \beta_{n}$ bağımsız değişkenlerin denklem katsayılarını ifade etmektedir ve tıpkı lineer regresyondaki gibi denklem katsayıları en küçük kareler yöntemiyle bulunur. Daha sonra elde edilen yeni bağımlı değişken değerleri ile olması gereken değerler arasındaki korelasyona ve diğer ilişkilere bakılarak elde edilen regresyon eğrisinin tahminindeki başarı ölçütü bulunmaya çalışılır.

Bunun dışında çok değişkenli regresyon eğrileri bağımlı değişkenlerin kareleri ya da bağımlı değişkenlerin birbiri ile çarpımı şeklinde olan denklemleri de içerebilir.

\section{UYGULAMA (APPLICATION)}

Kontrollü deneme yangınlarında zaman olarak ara değerler dâhil 151 veri seti elde edilmiştir. Bu veri setinden faydalanarak, elektronik tablolalama ortamında yanan alan elips formülüne(Pi x Büyük Eksen x Küçük Eksen) göre hesaplanmıştır. Böylece veri kümesinde bağımlı değişken olan alanla birlikte Tablo 3'deki gibi 9 büyüklük elde edilmiştir. Daha sonra toplam 151 satır olan bu büyüklükler Matlab ortamına aktarılmıştır.

Tablo 3. Bağımlı ve bağımsız değişken listesi

(Table 3. Dependent and independent variables list)

\begin{tabular}{|l|l|l|c|}
\hline Değişken Adı & Türü & Anlamı & Birimi \\
\hline Dead Material & Bağımsız & Ölü örtü fırınlanmış ağırlık & gr \\
\hline Humus & Bağımsız & Humus fırınlanmış ağırlık & gr \\
\hline Weed & Bağımsız & Diri örtü fırınlanmış ağırıık & gr \\
\hline DewPt & Bağımsız & Çiğ noktası & ${ }^{0} \mathrm{C}$ \\
\hline Relative Humidity & Bağımsız & Bağıı nem & yüzde \\
\hline Temperature & Bağımsız & Sıcakıık & ${ }^{0} \mathrm{C}$ \\
\hline Wind Speed & Bağımsız & Rüzgâr hızı & $\mathrm{m} / \mathrm{sn}$ \\
\hline Time & Bağımsız & Zaman & $\mathrm{sn}$ \\
\hline Area & Bağımıı & Yanan eliptik alan & $\mathrm{m}^{2}$ \\
\hline
\end{tabular}


Tuna, H. ve Erdem, O.A. NWSA-Technological Applied Sciences, 2A0085, 9, (2), 13-21.

Veri setinde yer alan değişkenlerden tutuşma sıcaklığına etki eden sıcaklık, nem ve çiğ noktası; yangının ilerlemesine etki eden rüzgâr, yakıt ağırlıkları ve zaman değişkenlerinin almış oldukları minimum ve maksimum değerler ise Tablo 4'deki gibi bulunmuştur.

Tablo 4. Bağımlı değişken maksimum ve minimum değeler (Table 4. Maximum and minumum values of dependent variables)

\begin{tabular}{|l|r|r|c|}
\hline Değişken Adı & Minimum Değer & Maksimum Değer & Birimi \\
\hline Dead Material & 91,42 & 272,73 & gr \\
\hline Humus & 123,56 & 1502,85 & gr \\
\hline Weed & 135,63 & 518,98 & gr \\
\hline DewPt & 3,90 & 8,50 & ${ }^{0} \mathrm{C}$ \\
\hline Relative Humidity & 21,00 & 30,00 & yüzde \\
\hline Temperature & 27,30 & 29,20 & ${ }^{0} \mathrm{C}$ \\
\hline Wind Speed & 0,00 & 12,90 & $\mathrm{~m} / \mathrm{sn}$ \\
\hline Time & 20,00 & 452,00 & $\mathrm{sn}$ \\
\hline
\end{tabular}

Bu veri seti Matlab programının istatistik araçları kullanılarak içerisinde sadece bağımsız değişkenlerin katsayılarının kullanıldığı çoklu regresyon analizine tabi tutulmuş ve analiz neticesinde R2 değeri $0.634(\mathrm{p}<0.01$ ve RMS=14.2) ve düzeltilmiş R2 değeri 0.613 bulunmuştur.

$y=1+x 1+x 2+x 3+x 4+x 5+x 6+x 7+x 8$

İkinci olarak bir önceki regresyon testinde kullanılan eğriye bağımsız değişkenlerin her birinin birbiriyle çarpımı eklenmiş ve oluşan yeni denklem için $R^{2}$ değeri $0.77\left(\mathrm{p}<0.01\right.$ ve RMS=12.4) ve düzeltilmiş $\mathrm{R}^{2}$ değeri 0.703 olmuştur.

$y=1+x 1+x 2+\cdots .+x 8+x 1 x 2+x 1 x 3+\cdots \ldots+x 8 x 7$

Üçüncü regresyon testinde ise ilk denkleme sadece bağımsız değişkenlerin karelerini içeren katsayılar eklenmiş ve bu denklem için $\mathrm{R}^{2}$ değeri $0.706\left(\mathrm{p}<0.01\right.$ ve RMS=13.0) ve düzeltilmiş $\mathrm{R}^{2}$ değeri 0.678 olarak bulunmuştur.

$$
y=1+x 1+x 2+\cdots .+x 8+x 1^{2}+x 2^{2}+x 3^{2}+\ldots .+x 8^{2}
$$

Son olarak regresyon testinde bağımsız değişkenlerin hem karesel hem de terimlerin birbiriyle çarpımı denenmiş ve bu regresyon çeşidi için $\mathrm{R}^{2}$ değeri $0.854(\mathrm{p}<0.01$ ve $\mathrm{RMS}=10.2)$ ve düzeltilmiş $\mathrm{R}^{2}$ değeri 0.802 bulunmuştur.

$$
y=1+x 1+x 2+\cdots .+x 8+x 1^{2}+x 2^{2}+x 3^{2}+\ldots .+x 8^{2}+x 1 x 2+x 1 x 3+\cdots+x 8 x 7
$$

Elde edilen bu son model için regresyon eğrisi ve \%95 güven aralığında dağılım grafiği ise Şekil 1'deki gibidir. 


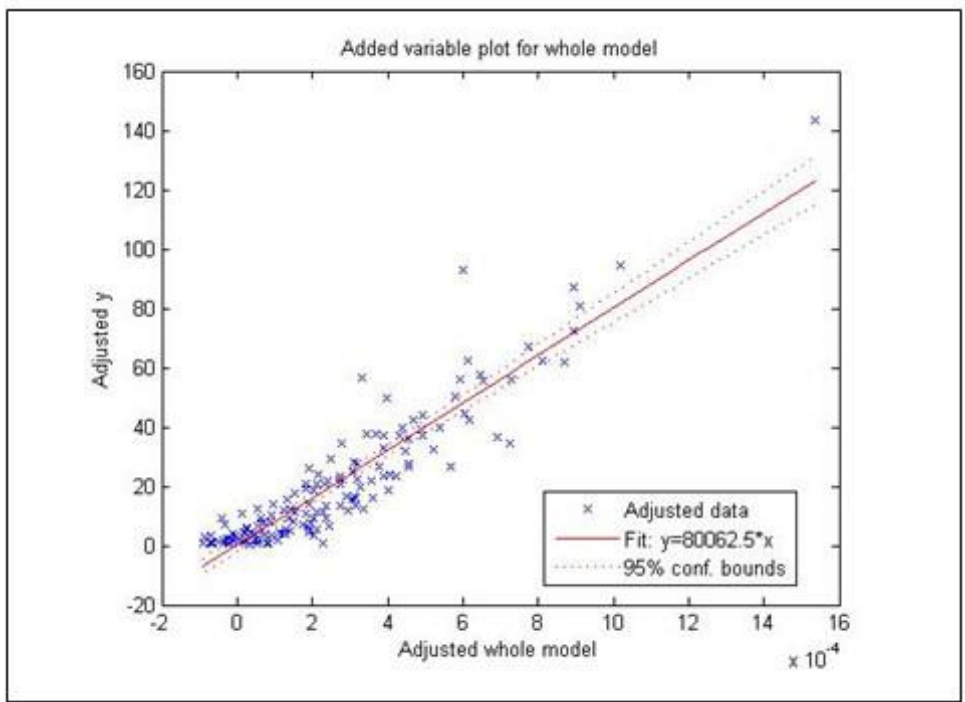

Şekil 1. Dağılım Grafiği

(Figure 1. Scatter Plot)

Yapılan regresyon deneylerinde meteorolojik değişkenlerin katsayıları ile sonucunda elde edilen p değerleri küçükten büyüğe doğru sıralandığında sırasıyla rüzgâr, sıcaklık, nem ve çiğ noktası elde edilmiştir. Bunun dışında bağımsız zaman değişkeni içeren denklem katsayıları en küçük $p$ değerlerini almıştır. Bunun dışında örtü ă̆ırlıklarının meteorolojik değişkenlere göre çok büyük p değerlerine sahip olduğu görülmüştür.

\section{SONUÇLAR (CONCLUSIONS)}

Kontrollü deneme yangın verileri kullanılarak elde edilen regresyon eğrilerinin başarı oranları birbirinden farklı çıkmıştır. Buna göre regresyon denklemindeki katsayılar arttıkça, daha iyi sonuç elde edilmiştir. Üç sonuç karşılaştırıldığında ise $\mathrm{R}^{2}$ değeri en fazla olan hem karesel hem de sabit terimlerden oluşan regresyon modeli daha başarılı olmuştur. Bunun dışında anlamlılık açısından tüm modellerin p değerleri $0.01^{\prime}$ in çok altında çıkmaktır. Bu da modelıerin kararlılığını göstermektedir.

Yapllan regresyon deneylerinde elde edilen en önemli sonuç elde edilen $p$ değerlerine göre rüzgârın en etkili meteorolojik değişken olduğudur. Çünkü yanmanın gerçekleşmesi için öncelikli olarak tutuşma sıcaklığına ulaşılması gerekir. Bunun için sıcaklığın yüksek, nemin ise düşük olması yeterlidir. Bu şartlar sağlandıktan sonra yanıcı madde tutuştuğu takdirde yangın rüzgârın etkisinde ilerlemesini sürdürecektir. Bundan sonra yangın kendi ısısını kullanarak önüne geçen yakıtları kurutacak ve bu şekilde yangın daha da çok ilerleyecektir.

Deney sonuçlarından elde edilen p değerlerine göre meteorolojik değişkenlerden sonra etkili olan değişkenler yakıttır. Bu sonuçlar yanmanın gerçekleşmesi için yakıtlarının neminin ne kadar önemli olduğunu ve bunun doğrudan meteorolojik şartlara bağlı olarak değiştiğini kanıtlamaktadır.

Yapılan deneylerde beklenen başka bir sonuç ise zaman bağımıı değişkeninin önündeki denklem katsayılarının en küçük p değerlerine sahip olmasıdır. Yangın başladıktan sonra ne kadar zaman geçerse o kadar yangın 
Tuna, H. ve Erdem, O.A. NWSA-Technological Applied Sciences, 2A0085, 9, (2), 13-21.

büyüyecektir. Bu da yangına ne kadar çabuk müdahale edilmesini gerektiğini açıkça göstermektedir. Eğer bir yangın ne kadar kısa sürede söndürülse o kadar az tehlikeli olacaktır.

Çalışmada dünyada var olan modelleri iyileştirmek yerine yeni bir modelin yapılabilirliği denenmiştir. Bunun için ölçümün iyi şekilde yapılması, yangının uygun kamera açılarında görüntülenmesi, gerekli güvenlik önlemlerinin alınması işin en can alıcı noktasıdır. Bu şekilde gerçeğe yakın ve tek noktadan çıkartılan yangının her aşaması gözlenmiştir.

Orman yangınlarını etkileyen diğer bir husus ise eğimdir. Çalışma sahası için izin alınan bölge eğimli olmadığı için bu faktör regresyon denklemlerinde kullanılmamıştır. Fakat sonraki çalışmalarda kontrollü yangınlar çıkartılıp, bu bağımsız değişken modellerde kullanılarak iyileştirmeler yapılabilir.

\section{KAYNAKLAR (REFERENCES)}

1. Dickinson, M.B., Johnson, E.A., and Artiaga, R., (2013). Fire spread probabilities for experimental beds composed of mixedwood boreal forest fuels. Canadian Journal of Forest Research-Revue Canadienne De Recherche Forestiere, Volume: 43, Number: 4, pp: 321330, DOI: 10.1139/cjfr-2012-0291.

2. Zhang, H., Han, X., and Dai, Sha., (2013). Fire Occurrence Probability Mapping of Northeast China With Binary Logistic Regression Model. Ieee Journal of Selected Topıcs in Applıed Earth Observatıons and Remote Sensing, Volume: 6, Number: 1, pp: 127-127, DOI: $10.1109 /$ JSTARS.2012.2236680.

3. Bisquert, M., Caselles, E., Sanchez, J.M., and Caselles, V., (2013). Application of artificial neural networks and logistic regression to the prediction of forest fire danger in Galicia using MODIS data. International Journal of Wildland Fire, Volume: 21, Number: 8, pp: 1025-1029, DOI: 10.1071/WF11105.

4. Bisquert, M.M., Sanchez, J.M., and Caselles, V., (2011). Fire danger estimation from MODIS Enhanced Vegetation Index data: application to Galicia region (north-west Spain). International Journal of Wildland Fire, Volume: 20, Number: 3, pp: 465-473, DOI: $10.1071 / \mathrm{WF} 10002$.

5. Martinez-Fernandez, J., Chuvieco, E., and Koutsias, N., (2013). Modelling long-term fire occurrence factors in spain by accounting for local variations with geographically weighted regression. Natural Hazards and Earth System Sciences, Volume: 13, Number: 2, pp: 311-327, DOI: 10.5194/nhess-13-311-2013.

6. del Hoyo, L.V. and Isabel, M.P.M, (2011). Logistic regression models for human-caused wildfire risk estimation: analysing the effect of the spatial accuracy in fire occurrence data. European Journal of Forest Research, Volume: 130, Number: 6, pp: 983-996, DOI: $10.1007 / \mathrm{s} 10342-011-0488-2$.

7. Cruz, M.G., McCaw, W.L., Anderson, W.R., and Gould, J.S., (2013). Fire behaviour modelling in semi-arid mallee-heath shrublands of southern Australia. Environmental Modelling and Software, Volume: 40, pp: 21-34, DOI:10.1016/j.envsoft.2012.07.003.

8. Kucuk, O., Bilgili, E., Bulut, S., and Fernandes, P.M., (2012). Rates of Surface Fire Spread in A Young Calabrian Pine (Pinus Brutia Ten.) Plantation. Environmental Engineering and Management Journal, Volume: 11, Number:8, pp: 1475-1480. 
9. Cao, X., Cui, X.H.L., Yue, M., Chen, J., Tanikawa, H., and Ye, Y., (2013). Evaluation of wildfire propagation susceptibility in grasslands using burned areas and multivariate logistic regression. International Journal of Remote Sensing, Volume: 34, Number:19, pp: 6679-6700, DOI: 10.1080/01431161.2013.805280.

10. Xue, Y., Liu, S.L., Zhang, L., and Hu, Y.M., (2013). Integrating fuzzy logic with piecewise linear regression for detecting vegetation greenness change in the Yukon River Basin, Alaska. International Journal of Remote Sensing, Volume: 34, Number:12, pp: 4242-4263, DOI: 10.1080/01431161.2013.775532.

11. Woolley, T., Shaw, D.C.L., Ganio, L.M., and Fitzgerald, S., (2012). A review of logistic regression models used to predict post-fire tree mortality of western North American conifers. International Journal of Wildland Fire, Volume: 21, Number:1, pp: 1-35, DOI: $10.1071 / \mathrm{WF} 09039$.

12. Weinberg, S.L. and Abramowitz, S.K., (2008). Statistics Using SPSS: An Integrative Approach. United Kingdom: Cambridge University Press.

13. Gordon R.A., (2012). Applied Statistics for the Social and Health Sciences. Routledge. 